\section{REVISTAS CONTRACULTURALES \\ ARGENTINAS EN DICTADURA Y TRANSICIÓN: DEBATES ALREDEDOR DEL EXILIO}

ARGENTINE COUNTERCULTURE MAGAZINES DURING DICTATORSHIP AND TRANSITION: DEBATES ABOUT EXILE

\author{
Evangelina Margiolakis \\ Universidad de Buenos Aires, Argentina \\ emargiolakis@gmail.com
}

Para citar este artículo:

Margiolakis, E. (2019). Revistas contraculturales argentinas en dictadura y transición: debates alrededor del exilio. Commons. Revista de Comunicación y Ciudadanía Digital, 8(2), 5-40. https://dx.doi.org/10.25267/COMMONS.2019.v8.i2.01

Fecha de recepción: 10/03/2019. Fecha de aceptación: 29/04/2019

\section{Resumen}

Durante la última dictadura argentina (1976-1983), un conjunto de publicaciones culturales desafió los límites impuestos por el poder hegemónico militar en relación con su propuesta de intervención político-cultural, su ubicación en el mercado de los bienes simbólicos y el rescate de tradiciones que confrontaron con la denominada cultura oficial, entre otros aspectos. Por esta razón, recibieron la denominación de revistas contraculturales, subterráneas o underground. A partir de 1978 y durante la denominada transición argentina, dichas publicaciones polemizaron con aquellas intervenciones que, desde el exilio, identificaron la producción cultural de quienes permanecieron desde la inacción, la quietud y el silencio. El exilio y la permanencia implicaron la construcción de redes de solidaridad en torno a padecer y denunciar los mecanismos de censura, prohibición y persecución del régimen militar. Sin embargo, también se estableció una serie de tensiones entre el "adentro" y el "afuera", que nos proponemos reponer en este artículo.

\section{Abstract}

During the last Argentine dictatorship (1976-1983), a group of cultural magazines challenged the restrictions imposed by hegemonic military power through their proposal of politic and cultural intervention, their place in the symbolic market and the recovery of traditions that contended against the so-called official culture, among other things. Consequently, they came to be designated as countercultural or underground magazines. Since 1978 and during the so-called Argentine transition, those magazines engaged in a dispute with those manifestations that, form the exile, equated their cultural production of those people who remained with the inaction, the stillness, and the silent. Between the exile and those who remained in the country, a solidarity network was established based on the suffering and denunciation of the military regime's censorship, prohibition, and persecution. But also a series of tensions between "inside" and "outside", which we intend to revisit in this paper, was established.

\section{Palabras clave}

Revistas culturales, dictadura militar, exilio, resistencia cultural, transición a la democracia

\section{Keywords}

Cultural magazines, military dictatorship, exile, cultural resistance, transition to democracy 


\section{Introducción}

El 24 de marzo de 1976, un helicóptero negro enviado por los rebeldes de servicio evacuó a Isabelita del Palacio de Gobierno en camisón. Un grupo de curiosos miraban y gesticulaban cerca de la Casa Rosada. Quizás llegaron a adivinar quién se iba en ese helicóptero, pero ciertamente, no tenían la menor idea de a quiénes ese helicóptero había traído. (César Fernández Moreno, 1981b: 50)

El golpe de Estado del 24 de marzo de 1976 en Argentina, llevado a cabo por las Fuerzas Armadas, contó con el apoyo de un sector de la sociedad vinculado con grandes corporaciones económico-financieras (sector empresarial o del capital concentrado), la Iglesia y los grandes medios de comunicación masiva, entre los actores más relevantes. El terrorismo de Estado instalado a partir del golpe militar trajo como consecuencia un plan sistemático de censura, represión y desaparición forzada de personas. Paralelamente instaló, de forma igualmente sistemática, un conjunto de políticas comunicacionales y de propaganda constitutivas de una dimensión productiva de discursos, orientadas a la ciudadanía, para lograr la "refundación" de un nuevo orden social. La dinámica de funcionamiento de la esfera cultural revela la coexistencia, junto a estos mecanismos represivos y de control, de una diversidad de prácticas. En particular, nos centraremos en aquellas que tuvieron lugar al margen, en los bordes o que desafiaron en algún aspecto estos mecanismos de control. En contraposición a la idea de que la dictadura implicó un proceso de silenciamiento o encierro, un conjunto de prácticas simbólicas surgió con el fin de recuperar la expresión y la posibilidad de desafiar los límites impuestos por el poder imperante. En este marco ubicamos a las revistas que recibieron en aquellos años la denominación de subterráneas o underground. 
Como señalamos, el régimen implementó tanto mecanismos de coerción fuerza o violencia por parte del Estado- como de consenso, a través de mecanismos de propaganda, sondeos de opinión y campañas públicas ${ }^{1}$. La cultura y la comunicación fueron concebidas como espacios estratégicos por diferentes actores sociales que llevaron adelante diferentes iniciativas culturales. Asimismo, tuvieron lugar un conjunto de experiencias que desafiaron el poder reinante y construyeron otros modos de hacer, decir y articular lo estético y lo político. En 1977, surgieron revistas culturales que fueron gestadas como órganos de difusión de grupos de estudio y formaciones culturales. Ellas desplegaron acciones que implicaron desafiar el poder imperante a partir de proponer temas, problemas y tradiciones que confrontaron con la política cultural oficial. Tales experiencias formaron parte de un conjunto de prácticas disidentes, caracterizadas por abordar "otra" agenda, cuestionar los dispositivos de prohibición, desafiar los límites de lo permitido, conformar grupos y articular esfuerzos a partir de la construcción de redes de solidaridad. Abordaremos el caso de las revistas culturales denominadas indistintamente - por sus protagonistas - alternativas, subterráneas, underground o contraculturales. Tales publicaciones implicaron un modo de disputa y desafío del poder, en aspectos como su proyecto editorial - alejado de la dinámica mercantil de los grandes medios-, su forma de concebir la relación entre estética y política y su modalidad de intervención en la esfera pública, aun cuando sus modos de circulación debieran ser preservados. En particular, se trató de experiencias que, aunque diversas y heterogéneas, construyeron redes de solidaridad, conformaron colectivos de revistas, compartieron preocupaciones, reclamos o críticas al régimen, desarrollaron diversas tácticas tendientes a desafiar y a crear espacios de contención al mismo tiempo. En contextos represivos, construir ámbitos de articulación de experiencias implicó desafiar la lógica de atomización social impuesta por el poder militar.

1. El trabajo de investigación doctoral de Julia Risler (2019) indaga en esta zona, planteando que el régimen militar basó su dominio en dos estrategias. Por un lado, en un plan sistemático de represión y por el otro, en la creación de políticas culturales, educativas y comunicacionales orientadas a regular la opinión pública y disciplinar a la sociedad, generando formas de consenso y amedrentamiento al conjunto de la sociedad. 
La prensa subterránea tuvo como antecedentes aquellas publicaciones que presentaron una opción diferencial frente al mercado o al predominio de una "estética oficial" y se multiplicaron en un contexto caracterizado por la imposición de dispositivos de represión y censura (Rivera, 1995). La idea de un periodismo independiente que privilegiaba la libertad poética estuvo presente entre los elementos comunes de este tipo de publicaciones denominadas subterráneas, "subte", under o underground ${ }^{2}$. El estudio de la prensa subterránea no puede abordarse sino en relación con el contexto de censura y represión presente en la última dictadura cívico-militar argentina. En este sentido, el universo de estas revistas se configuró a partir de la disidencia respecto del discurso del régimen, diferenciándose en cuanto al rescate de prácticas simbólicas que se opusieron a la cultura oficial, su carácter no comercial y el rescate de la libertad aun en contextos de autoritarismo.

Por su parte, el concepto de "alternatividad" o "comunicación alternativa" se refiere a un tipo de periodismo que propone la elaboración de una agenda diferente de la prensa hegemónica, esta última caracterizada por su lógica comercial, o bien por reproducir los valores de la cultura oficial. En la década de 1970, el concepto fue reapropiado en América Latina. Describió un modelo de comunicación diferente al de los medios masivos comerciales, representantes de la cultura dominante. Sus cualidades consistieron en el acceso igualitario, la participación en la producción de mensajes y la toma de decisiones colectivas con el fin de dar voz a grupos relegados de la sociedad para que ellos recuperaran la posibilidad de tomar la palabra. Más allá de las diferencias respecto de su definición, en particular, la discusión acerca de si la comunicación alternativa debía estar inscripta en una praxis transformadora de la estructura social (Graziano, 1980), la alternatividad fue explicada como una opción diferencial frente a la estructura de propiedad, forma de organización y contenidos que habían adoptado los medios masivos hegemónicos (Simpson Grinberg, 1986).

2. En Estados Unidos, el surgimiento de la prensa underground o contracultural coincidió con la emergencia de los movimientos beat y hippie, lo que creó el "Underground Press Syndicate" — Sindicato de Prensa Subterránea-. En Argentina, la prensa "subte" tuvo sus orígenes hacia fines de la década de 1960, a partir del golpe militar de Juan Carlos Onganía (1966-1970), con publicaciones como Eco Contemporáneo o Contracultura, que crecieron tras el impacto del Mayo Francés de 1968 (Rivera, 1995). 
Respecto de este tipo de publicaciones ubicadas en el espacio de la contracultura - que son nuestro objeto de estudio-, Cecily Marcus (2002) resulta un aporte destacado. Plantea que estas revistas se encargaron de señalar las inquietudes de las generaciones más jóvenes, no solo en lo referente a la literatura y las definiciones políticas, sino también a otras disciplinas. Los artículos incluyeron la crítica, la praxis política y la reseña estética, permitiendo una extensa variedad de temas y enfoques ${ }^{3}$. En este trabajo nos proponemos reponer las discusiones suscitadas alrededor del exilio, generadas desde algunas publicaciones contraculturales de Argentina como respuesta a reflexiones producidas por intelectuales argentinos, que colaboraron en revistas editadas en el exterior, tales como Eco (Colombia), Tiempos Modernos (Francia) y Controversia (México), entre otras.

El plan sistemático represivo llevado adelante por la dictadura cívico-militar argentina desde 1976 obligó a miles de ciudadanos de Argentina, entre ellos numerosos intelectuales y productores culturales, a refugiarse en el exilio, a fin de escapar de la tortura y desapariciones. A partir de 1978, desde el exterior, se multiplicaron las denuncias al régimen represivo argentino desde diversos organismos de Derechos Humanos. Con ocasión del Mundial de Fútbol que tuvo lugar en Argentina en ese año, diversas intervenciones de intelectuales en el exterior denunciaban la existencia de campos de concentración. En ese marco, varias publicaciones producidas en diferentes países de Europa y América Latina, reclamaban por el paradero de los desaparecidos y se solidarizaban con las víctimas del terrorismo de Estado ${ }^{4}$.

\footnotetext{
3. Como parte del trabajo de investigación doctoral que he realizado, y debido a que gran parte de las fuentes documentales se encontraban inéditas, junto a otros investigadores e investigadoras, hemos confeccionado una plataforma virtual en la que se encuentran algunas publicaciones subterráneas. Las mismas se encuentran disponibles en la siguiente página: www.archivosenuso.org

4. Fue el caso de revistas tales como Controversia (1979-1981), editada en México y Resumen de la Actualidad Argentina (1979-1983), editada en Madrid por el Club para la Recuperación Democrática Argentina.
} 
Desde las revistas subterráneas de Argentina, se generaron algunas discusiones que produjeron una divisoria de aguas entre el "adentro" y el "afuera", surgidas como réplica a la idea - construida en el exilio- de inexistencia o silenciamiento de cualquier iniciativa cultural que se pudiera gestar desde Argentina. Por el contrario, la presencia de publicaciones contraculturales o subterráneas daba cuenta de una actividad que, aunque fragmentada y en los márgenes, presentaba la intención de dejar lugar a voces disidentes. Aquellos productores culturales que permanecieron en el país, se vieron en la necesidad de plantear que aquella "inacción" con la que se había caracterizado desde afuera el clima local, consistía en una mera ilusión o construcción mítica. Desde la permanencia, se describían múltiples iniciativas culturales y editoriales, lo que ponía en cuestión una mirada que había generado como efecto su invisibilización. El exilio, las persecuciones, los mecanismos de censura y de disciplina fueron consecuencia del terrorismo de Estado tanto en el país como para quienes se habían visto obligados a emigrar. Sin embargo, en algunos momentos, se produjo una confrontación entre quienes "se fueron" y quienes "se quedaron", entre exilio y permanencia. Es por ello que nos propusimos indagar en las discusiones entre el "afuera" y el "adentro" suscitadas en las publicaciones contraculturales argentinas, con la intención de explicar el sentido de aquellas intervenciones, las cuales implicaron la necesidad de crear condiciones de legibilidad para fenómenos que, en el marco de la dictadura, permanecieron invisibilizados durante varios años. En particular, intentamos reconstruir los ejes de las polémicas entabladas por publicaciones subterráneas producidas en la permanencia argentina -El Ornitorrinco, Sitio y Praxis-, como respuesta a diversas declaraciones realizadas desde publicaciones en el exilio, tales como Controversia —editada en México-y Tiempos Modernos —editada en Francia-, entre otras intervenciones. 


\section{Aproximaciones teóricas y metodológicas}

\subsection{Marco teórico}

Para comprender las prácticas que son nuestro objeto de estudio, el materialismo cultural de Raymond Williams nos permite abordar, en particular, el concepto de hegemonía, que refiere a un complejo entrelazamiento de fuerzas que no se realiza en forma pasiva sino que presenta límites y presiones específicas y cambiantes (Williams, 1988). Toda hegemonía es continuamente resistida, recreada y modificada, tiene elementos que se le oponen y resisten. Aunque con matices, en este espacio de oposición, disidencia o resistencia encontramos las revistas contraculturales y otras prácticas, cuya existencia implicó una relación de disputa, confrontación o tensión con el poder militar.

Asimismo, desde esta perspectiva, Williams diferencia las instituciones, como formas de organización perdurables en el tiempo con reglas y leyes, del concepto de formaciones - vital para comprender las prácticas que son nuestro objeto de análisis - que alude a grupos culturales, movimientos - literarios, artísticos, filosóficos o científicos- que inciden en la dinámica cultural en determinado momento histórico. Los define como:

los movimientos y tendencias efectivos, en la vida intelectual y artística, que tienen una influencia significativa y a veces decisiva sobre el desarrollo activo de una cultura y que presentan una relación variable y a veces solapada con las instituciones formales. (Williams, 1988: 141) 
Esta red de relaciones conceptuales, permite a Williams observar el carácter dinámico de una cultura $\mathrm{y}$, asimismo, reconocer elementos en tensión. En este sentido, las experiencias analizadas, surgidas como iniciativas de grupos culturales o formaciones, disputaron en algún aspecto el poder hegemónico militar y revelan el dinamismo de la esfera cultural. El surgimiento de estos proyectos editoriales nos permite entonces reconocer la existencia de grupos culturales o formaciones, nucleadas alrededor de las revistas, que funcionaron como órganos de difusión de ideas e inquietudes de estos grupos.

Respecto de la relación entre lo hegemónico y lo subalterno, Williams posibilita plantear que, si bien toda hegemonía implica dominio, este no se ejerce de un modo total y definitivo, sino que es constantemente desafiado, lo que genera cuestionamientos que alteran su modo de funcionamiento. Con la intención de retomar la categoría de subterráneo y su relación con movimientos contraculturales o de resistencia, el aporte de Williams nos resultó muy significativo ya que nos permite observar la interacción dinámica entre prácticas hegemónicas y de resistencia, indagando en estos espacios que permiten reconstruir las experiencias que analizamos y los modos en que ellas desafiaron el poder hegemónico militar.

Por otra parte, cabe aclarar que, al mencionar el período dictatorial en Argentina (1976-1983), es necesario establecer diversas etapas al interior de este lapso y en relación con la dinámica de las publicaciones culturales. En los últimos años, diversas investigaciones coinciden en señalar la necesidad de establecer diferentes momentos al interior del período de la última dictadura cívico-militar argentina (1976-1983). Tal es el caso de Marina Franco (2018), quien afirma que a partir de 1979 comenzaron a vislumbrarse algunas voces disidentes y críticas hacia el régimen, indagando en aquellos relatos presentes en la sociedad argentina -y replicados en el exterior - acerca del reclamo por la represión y las desapariciones forzadas. Por su parte, Paula Canelo $(2008,2016)$ refiere a diferentes etapas al interior del período dictatorial a partir de analizar la relaciones entre los distintos sectores que conformaron el poder militar. Una primera etapa se dio en el momento inmediatamente posterior al golpe, la cual se caracterizó por la cohesión interna - del aparato militar-, construida alrededor de la lucha antisubversiva. A partir de 1979, la autora describe la crisis interna que se gestó en la cúpula militar. 
En sintonía con estos planteos -aunque con rasgos propios-, desde el universo de la prensa subterránea o de resistencia, es posible identificar una primera etapa a partir de 1977, cuando surgieron y se multiplicaron revistas culturales que fueron gestadas como órganos de difusión de grupos de estudio y formaciones culturales que intentaron recuperar la expresión. Una segunda etapa se inicia hacia 1979, cuando los organismos internacionales - como la Comisión Interamericana de Derechos Humanos (CIDH) - y diversos intelectuales en el exilio, se hicieron eco de las denuncias de los organismos de Derechos Humanos locales acerca de la desaparición forzada de personas, intentaron presionar al régimen y se solidarizaron con quienes experimentaban las persecuciones (Canelo, 2008, 2016). En este período, se conformaron redes y agrupamientos, como ARCA - Asociación de Revistas Culturales Argentina-y ARA -Asociación de Revistas Alternativas-, colectivos de teatro y de otras disciplinas, lo que significó llevar adelante un cuestionamiento más abierto al régimen. Una tercera etapa se puede identificar hacia 1982, cuando se produjo un resquebrajamiento más visible del régimen. En este período diferentes organismos internacionales denunciaron abiertamente el genocidio que había sido perpetrado por el régimen. También en ese año, y después de la derrota en Malvinas, comenzó a discutirse con mayor profundidad alrededor de la idea de "transición a la democracia" y diversas prácticas e iniciativas ubicadas en el espacio de la resistencia cultural se sumaron al reclamo del retorno a la institucionalidad democrática. En las revistas contraculturales, esta temática - acompañada de diferentes y contrastantes miradas - constituyó uno de los ejes centrales de los debates. En el contexto latinoamericano, el concepto de transición fue concebido como el rumbo que debían tomar los autoritarismos en el marco de un proceso de profesionalización de los estudios políticos (Lesgart, 2002). Cabe aclarar que, aunque con matices, la idea de transición comprende los últimos años de la dictadura y primeros de la posdictadura. Por lo tanto, la periodización analizada nos permite trazar algunos lineamientos a fin de observar desplazamientos y transformaciones en las prácticas analizadas. 
A su vez, nos interesa rescatar distintos trabajos acerca del exilio y la conformación de redes de solidaridad con Argentina. En primer lugar, Moira Cristiá (2017) analiza la resistencia antidictatorial que tuvo lugar en París en los años ochenta a partir de la conformación del colectivo AIDA (Asociación Internacional de Defensa de Artistas Víctimas de la Represión en el Mundo), como ejemplo de cooperación en la denuncia que diversos actores culturales emprendieron a fin de cuestionar la legitimidad del régimen militar argentino. Asimismo, Marina Franco (2008) describe las redes de solidaridad entabladas en Francia entre exiliados y militantes franceses.

También resulta importante señalar una serie de investigaciones que retoman el universo de revistas culturales subterráneas en el contexto de la última dictadura argentina. José Luis de Diego (2007) describió la experiencia de estas revistas, considerándolas como un espacio de disputa de la hegemonía. Identificó algunos ejes de discusión en ellas, concibiendo que se trató de un espacio de resistencia cultural ejercido desde el campo literario. Por su parte, los trabajos de Roxana Patiño (2006) describieron un conjunto de publicaciones denominadas de resistencia o disidencia a la dictadura, caracterizadas por una postura común frente al contexto de opresión cultural.

Por su parte, nos interesa contextualizar la noción de resistencia. Esta nos remite a un conjunto de prácticas y, asimismo, a una serie de reflexiones en el campo de la investigación sobre la producción simbólica. En este marco, la categoría de resistencia fue utilizada en Argentina en la década de 1980, en un contexto de apropiación particular de los Estudios Culturales Ingleses, entre otras perspectivas. Ello permitió abrir una etapa de problematización acerca de la recepción. Respecto de las prácticas, la noción de cultura de la resistencia incluyó en Argentina un amplio espectro de experiencias como las revistas "subte", el cine de denuncia, la música popular, el rock, la narrativa elíptica y metafórica de autores como Ricardo Piglia y Haroldo Conti, entre otras. Dichas prácticas tuvieron en común la conformación de frentes y redes de articulación que constituyeron así espacios de socialización de inquietudes e intereses. 
En particular, la noción de resistencia molecular — que será retomada en el trabajo - remite al pensamiento de Deleuze y Guattari (1977). Para los autores, la idea de "rizoma", que dio lugar a pensar la resistencia molecular, remitía a principios de conexión y heterogeneidad. El rizoma - en referencia a las células - presentaba como cualidad un principio de multiplicidad, consistente en la posibilidad de generar tramas y agrupamientos. Esta clave interpretativa fue proyectada sobre las prácticas que son nuestro objeto de análisis y que Brocato (1986, 1993) describió como "actividades moleculares" tendientes a recomponer alguna parte del tejido social. Tal enfoque permitió entonces pensar en experiencias diversas y múltiples que conformaron iniciativas que, desde espacios micro, construyeron conexiones, tramas y relaciones, desafiando en algún aspecto la tendencia a la atomización y la segmentación social alentada por el régimen militar.

\subsection{Abordaje metodológico}

Desde el punto de vista metodológico, hemos abordado un corpus de publicaciones relevantes que nos permite reponer diversas discusiones, en particular, aquellas centradas en torno al exilio y suscitadas desde las revistas contraculturales que son objeto de nuestro análisis. El punto de partida han sido tres publicaciones surgidas en Buenos Aires, que dedicaron varios artículos o bien, un dosier específico a generar reflexiones acerca de la temática del exilio y en particular, discutiendo con miradas construidas desde el exterior y concebidas como homogeneizantes desde la permanencia. Ellas fueron, en primer lugar, la revista literaria El Ornitorrinco -dirigida por el escritor Abelardo Castillo y editada entre 1977 y 1986-, de la cual abordaremos la discusión que entabló Liliana Heker con el escritor Julio Cortázar. En segundo lugar, la revista literaria Sitio —editada entre 1981 y 1987-, que publicó un dosier sobre exilio en 1983 en el que escribieron sus principales referentes en abierta polémica con un número especial — dirigido por David Viñas- de Tiempos Modernos, revista editada en Francia. Dicho número especial estuvo dedicado a analizar la situación de Argentina en el marco de la última dictadura. Por último, la revista Praxis —dirigida por Emilio Cafassi y editada entre 1983 y 1986- que publicó un 
artículo de Carlos Brocato, quien confrontó con la mirada de algunos intelectuales nucleados alrededor de la revista Controversia. Estos debates, y en particular aquellos entablados por Sitio y Praxis, nos permiten reponer ciertos marcos interpretativos que se corresponden con las discusiones iniciadas en la transición democrática tales como el reconocimiento de la existencia de una cultura de la resistencia gestada en tiempos de la dictadura argentina que intentaba desafiar los mecanismos del régimen. Si bien repondremos contextualmente las publicaciones y materiales textuales producidos en el exilio - que fueron objeto de la respuesta por parte de las revistas contraculturales-, nuestro punto de partida estará centrado en reconstruir las discusiones, polémicas y debates desde las revistas culturales de Argentina.

Para caracterizar estas experiencias, elaboramos una matriz de análisis de publicaciones que tendió a reconstruir sus condiciones de producción y circulación, la interacción con el contexto, así como los tópicos de discusión alrededor del exilio. Por lo tanto, para este trabajo, hemos abordado tres revistas culturales disidentes respecto de la política oficial del régimen y editadas en Buenos Aires. Se han seleccionado tomando en cuenta la existencia de polémicas entabladas en su interior con publicaciones del exilio: El Ornitorrinco (19771986). Director: Abelardo Castillo; Praxis (1983-1986). Consejo de Redacción: Laura Rossi, Gabriel Rot, Horacio Tarcus, Alejandro Conti, Carlos Brocato; y Sitio (1981-1987). Editores: Ramón Alcalde, Héctor Grisafi, Luis Gusmán, Jorge Jinkis y Eduardo Grüner.

Por último, resulta necesario aclarar que la existencia de una literatura del exilio remite a un universo heteróclito que comprende diversos géneros a partir de los cuales se intentó nombrar e interpretar el desgarro producido por la necesidad de marcharse del país de origen. Este tipo de literatura, más que constituirse como un único género, incluye diversos géneros literarios como la novela, el testimonio, la poesía y el cine, las polémicas en revistas culturales - que retomaremos en este trabajo-, entre otros discursos que tematizaron sobre el exilio forzado. 


\section{El primer antecedente: Liliana Heker desde El Ornitorrinco}

El Ornitorrinco fue concebida por sus editores como una revista literaria inspirada en el existencialismo de Jean Paul Sartre. Su director, Abelardo Castillo (1935$2017)^{5}$, contaba con una reconocida trayectoria como escritor y, asimismo, como director de las revistas literarias El Escarabajo de Oro (1959-1960) y El Grillo de Papel (1961-1974). En el caso de El Ornitorrinco, contó en su staff con la presencia de jóvenes escritores, entre ellos, Liliana Heker, escritora argentina nacida en Buenos Aires en 1943.

Hacia 1980, Heker polemizó con un artículo de Julio Cortázar6, titulado "América Latina: exilio y literatura", que había sido publicado dos años antes (noviembre de 1978) en la revista colombiana Eco n. - 205. En el texto, Cortázar manifestaba su preocupación frente al "genocidio cultural", refiriéndose a la opresión que se encontraba padeciendo la Argentina en esos años de la dictadura. Asimismo, el escritor esbozaba la existencia de una literatura del exilio. La intención primordial de Cortázar había apuntado a denunciar los mecanismos de censura y represivos del régimen, que identificaba a los exiliados como "enemigos" y como parte de la campaña "antiargentina". Sin embargo, su alocución excedió su propósito de denuncia del régimen y fue producto de otras lecturas, críticas y desvíos.

A partir del artículo de Cortázar, Heker inició una réplica a su planteo en el séptimo número de El Ornitorrinco (1980) y continuó en el décimo (1981), con la respuesta de Cortázar y una nueva intervención de la autora. Para Liliana Heker, un "milagro" parecía haber borrado los matices en la mirada del escritor, generando la construcción de dos universos antagónicos: los radicados en el exterior, "condenados a vivir lejos de su patria", y los radicados en Argentina, "mártires o muertos en vida". Heker planteaba no dudar de las buenas intenciones del escritor — basadas en su solidaridad con quienes habían permanecido tanto como con quienes se habían exiliado-, aunque sin embargo, intentó discutir

5. Abelardo Castillo dirigió las revistas mencionadas, las cuales retomaron el existencialismo de Jean Paul Sartre. En la dictadura permaneció en el país escribiendo y editando El Ornitorrinco, nombre que remitía a un animal raro, mezcla de muchos seres, que tenía como cualidad principal "mirar para arriba y a los costados".

6. Durante la última dictadura argentina, el escritor Julio Cortázar permaneció en París, Francia. Allí formó parte de diferentes colectivos de artistas que denunciaron al régimen argentino. 
con su interpretación. Para Heker, el artículo publicado en el exilio por Julio Cortázar reproducía una lectura errónea y esquemática de lo que sucedía en el país, presentando así el riesgo del apresuramiento y una serie de recursos más pasionales que científicos: "Cortázar generaliza, hace del 'de afuera' y del 'de adentro' dos condenados sin atenuantes, acomoda la situación de todos los intelectuales residentes en Latinoamérica a los requerimientos de su artículo y, con dolor, nos aplasta de un plumazo" (Heker, 1980: 3). La escritora se detuvo, en particular, en el proceso de mistificación al que habían sido sometidos tanto el "afuera" como el "adentro". Para Heker, el planteo de Cortázar tenía, como intención central, transmitir la "amargura" del exilio forzoso de esos años y el desgarramiento que había producido la dictadura desde 1976. Aunque su partida del país había sido previa al golpe, su argumento se centraba en su condición de exiliado imposibilitado de retornar luego del último golpe militar. Heker quiso discutir, especialmente, con la afirmación de Cortázar acerca de la inexistencia de jóvenes escritores durante la última dictadura, ya que ella misma representaba una generación de escritores que había permanecido asumiendo el riesgo de transformar su realidad. Para la colaboradora de El Ornitorrinco, Cortázar generalizaba y dramatizaba, mientras que su planteo se proponía romper con la idea de "héroe" o "mártir" debido a que el exilio o la permanencia no constituían en sí mismos un valor ético. La autora finalizaba el artículo señalando su incomodidad respecto de las modas de París que planteaban una permanencia signada por la "muerte". En noviembre de 1980, Cortázar le respondió con su "Carta a una escritora argentina", destacando que, más que las diferencias, tenían en común el padecimiento y dolor por los mecanismos de censura y represión. La carta se publicó en El Ornitorrinco casi un año después. Para el escritor, no era necesaria la polémica sino el diálogo:

Tenés toda la razón, Liliana, no somos ni héroes ni mártires; una vez más somos gente barrida afuera y adentro. Discutir estas cosas entre nosotros es perder un tiempo que no pierden los que nos barren y nos aplastan; por eso no te he contestado para polemizar, como creo que tampoco vos me escribiste para eso. (Cortázar \& Heker, 1981: 4) 
El argumento de Cortázar, realizado en un tono de diálogo respetuoso, señalaba que, en verdad, la polémica se debía entablar con el régimen, el principal oponente tanto de los exiliados como de los que habían permanecido. Heker le respondía nuevamente unos meses después y en ese mismo número de la revista, indicando que la censura que había denunciado Cortázar justamente había sido desafiada por muchas revistas ubicadas en el territorio de lo subterráneo, entre ellas, El Ornitorrinco:

Es cierto, la censura vuelve nuestra prosa menos explícita; pero también es cierto que la realidad hace a nuestras palabras más eficaces (...). Declaraciones, solicitadas, movimientos teatrales, talleres literarios, revistas de literatura, son hechos que usted sin duda ignora. Usted vive en París y, al parecer, confía en los suplementos dominicales. No son buenas maneras de entender la realidad de nuestro país. (Cortázar \& Heker, 1981: 7)

Heker enumeraba una serie de intervenciones culturales que, desde su mirada, rompían con la idea de inacción. Como ejemplo de quienes habían permanecido produciendo de forma "comprometida", situaba entre otros, a escritores, músicos y productores culturales tales como, los escritores Armando Tejada Gómez, Abelardo Castillo, Juan José Manauta, Beatriz Guido, Ricardo Piglia y Ana María Shua, así como los dramaturgos Osvaldo Dragún y Eduardo Pavlovsky. Para Heker, la construcción mítica desde el exilio impedía visualizar los desafíos a la censura por parte de los que habían optado por la permanencia. Aunque el propósito de Cortázar consistió en polemizar con el régimen y denunciar sus mecanismos de terror, su intervención fue leída por Heker como una mirada mitificadora desde el exilio que no podía "ver" el dinamismo cultural que se gestaba en estas latitudes.

Aquello que unía el "afuera" y el "adentro" era la denuncia de la dictadura. Las críticas de Cortázar se dirigían al régimen. Sin embargo, la idea de que la dictadura había arrasado con todo, generó como efecto la necesidad de identificar aquellas prácticas que no habían sido arrasadas ni silenciadas. El argumento de quienes permanecieron intentaba explicar que, aun en condiciones de censura y prohibiciones, se podía pensar en prácticas culturales que habían conformado un universo de resistencia o disidencia frente al poder castrense. 
La polémica suscitada en la revista generó posteriormente nuevas réplicas desde quienes habían padecido el exilio. Humberto Costantini ${ }^{7}$ (1924-1987), escritor que había formado parte de El Escarabajo de Oro y El Grillo de Papel -revistas dirigidas por Castillo en décadas anteriores-, retornaba del exilio en México en 1984. El 13 de abril de ese año, escribía en la revista El Observador. Lo hacía en defensa de su amigo Cortázar y polemizando con Abelardo Castillo y Liliana Heker. Para Costantini, ambos se habían permitido hablar "algo más que despectivamente" de los exiliados, tal vez por afán de figuración e inventando una supuesta polémica. El exilio implicó dolores, desgarros y polémicas entre el afuera y el adentro. No obstante, desde ambos espacios, se intentaban desarrollar algunas tácticas de subsistencia en el marco de un poder "desaparecedor" (Calveiro, 1998).

Como señalamos, más tarde, hacia 1983, el debate continuó en revistas como Sitio, que polemizó con un número especial dirigido por David Viñas ${ }^{8}$ en la revista Tiempos Modernos, publicada en Francia. También se produjo en Praxis, de la mano de su colaborador, Carlos Brocato. Las discusiones gestadas desde las publicaciones contraculturales de Argentina apuntaron a romper con una mirada dicotómica y mitificadora con la intención de reconstruir el fenómeno de manera más compleja. Para Brocato, las revistas subterráneas fueron un ejemplo de cómo romper con la idea de aquietamiento con la que se había caracterizado la situación cultural del país desde el exilio. La transición implicó volver a mirar aquellas prácticas surgidas en los márgenes, solapadas, fragmentadas y que, sin embargo, subsistieron en contextos de dictadura.

7. El escritor Humberto Costantini debió exiliarse en México durante la última dictadura argentina. Había militado en los años previos en el PRT-ERP y también había formado parte del staff de las revistas literarias dirigidas por Abelardo Castillo. En 1983, retornaba del exilio. Murió en Buenos Aires en 1987.

8. David Viñas (1927-2011) fue director — junto con su hermano Ismael— de la revista Contorno (19531959) y en la década de 1960, publicó Literatura argentina y realidad política. Contorno constituyó un punto de inflexión y un aporte al campo del periodismo cultural que configuró un modo de intervención intelectual que retomó discusiones dentro de las izquierdas sobre el peronismo, polemizando también con el socialismo y su propuesta de neutralidad respecto de la invasión norteamericana a Guatemala. Se posicionó como un proyecto oposicional a la revista Sur, la cual se propuso la difusión de literatura especialmente europea al público de habla hispana (Rivera, 1995). Para Contorno, la revista Sur representaba el "antiperonismo colonialista". 


\section{Imagen 1}

El Ornitorrinco 7. Enero-Febrero 1980

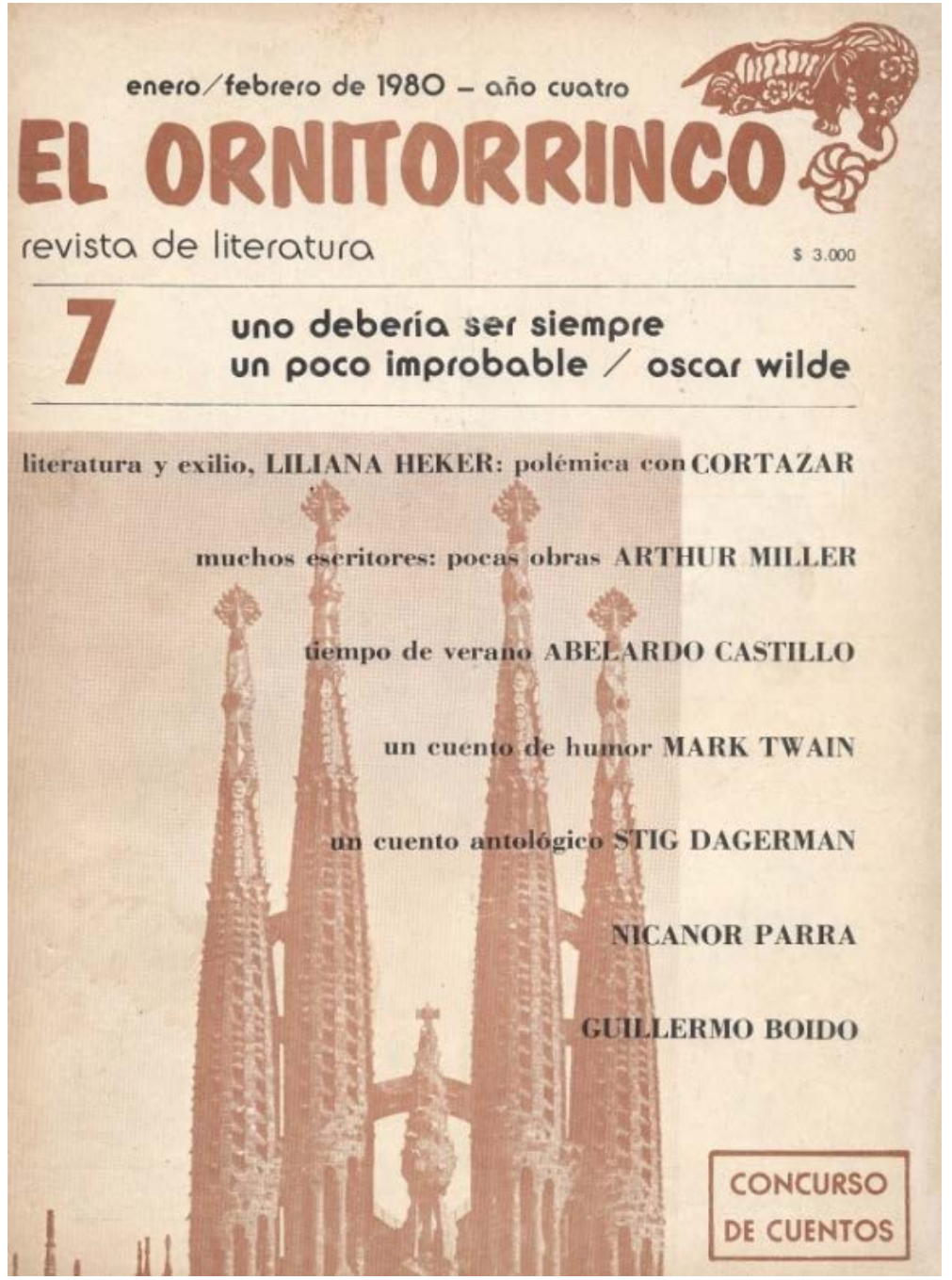

Fuente: Archivo personal de Abelardo Castillo 


\section{Los últimos años de la dictadura argentina: los debates desde Sitio y Praxis}

\section{1. La polémica de Sitio con Tiempos Modernos}

Fechado en julio-agosto de 1981, la revista francesa Tiempos Modernos ${ }^{9}$ editaba un número especial (n. ${ }^{\circ}$ 420/21) sobre Argentina en tiempos de dictadura, coordinado por David Viñas y César Fernández Moreno ${ }^{10}$, en el que participaron otros intelectuales argentinos, mayoritariamente residentes en el exilio francés. Dicha edición especial se tituló "Argentina: entre el populismo y el militarismo" (Viñas \& Fernández Moreno, 2011) y estuvo dividida en temáticas o apartados. La primera parte, "Entradas en la materia", consistió en una serie de quince artículos y un cuadro cronológico, firmados por David Viñas y César Fernández Moreno. Asimismo, otros apartados fueron firmados por escritores e intelectuales en el exilio, tales como Juan Carlos Portantiero, Osvaldo Bayer, León Rozitchner, Hipólito Solari Irigoyen, Julio Cortázar, Noé Jitrik, Juan José Saer, Francisco Urondo y Juan Gelman, entre otros. Los apartados, que implicaron esfuerzos analíticos, se titulaban: "Los hechos y lo previo", "Las fuerzas políticas", “QQué es la literatura?”, la sección "Otras formas de decirlo" — con poemas-, la sección dedicada a "Testimonios" y, por último, la sección "Conclusiones". Usaron seudónimos David Viñas - quien en algunos artículos firmó como Antonio J. Cairo- y argentinos residentes en su país, como fueron los casos de Beatriz Sarlo - integrante de la revista Punto de Vista-, Fabián Escher y Julia Thomas —estos dos últimos escritores y colaboradores de la revista subterránea Nudos-.

9. Fundada en 1945 por Jean Paul Sartre, Simone de Beauvoir y Maurice Merleau-Ponty.

10. Escritor argentino nacido en Buenos Aires en 1919, hijo del escritor Baldomero Fernández Moreno. En la última dictadura permaneció en París, donde murió en 1985. 
Los textos que conformaron las entradas en la temática -elaborados por sus coordinadores - ofrecían claves de lectura vinculadas con la tragedia de la dictadura y el exilio, así como el desgarramiento por la patria "amada", "soñada" y "perdida". César Fernández Moreno - muerto en 1985 en París - lo planteaba en "Las ilusiones del enamorado", uno de los primeros artículos de este número especial:

\begin{abstract}
¿Es la Argentina con la que soñamos todos, con la que hemos coexistido en tiempos y espacios parciales? Este número especial no nos servirá solamente de catarsis, sino también de clave, permitiéndonos resolver el problema capital que nos plantea nuestra patria amada: seguir amándola tal como creemos que es, o si no es tal como la soñamos, sacar las consecuencias y tratar de olvidarla, es decir, asumir así nosotros nuestro error afectivo. (Fernández Moreno, 1981a: 30)
\end{abstract}

En esas mismas "Entradas", David Viñas trazaba paralelismos entre el primer golpe de Estado en Argentina de 1930 y el golpe de 1976, señalando el desplazamiento que explicaba el pasaje de los melancólicos legionarios de entonces a los tecno-burócratas de hoy: "En los años 30 la manipulación de las capas populares se hizo por intermedio del Congreso Eucarístico Internacional celebrado en Buenos Aires; la reciente manipulación de las capas populares se hizo gracias al campeonato mundial de fútbol de 1978" (Viñas, 1981: 44). Viñas denunciaba la operación ideológica perpetrada por el régimen durante el Mundial de Fútbol de 1978, en el mismo momento en los organismos de Derechos Humanos internacionales denunciaban el horror del terrorismo de Estado. Mientras que, en ocasión del Mundial de Fútbol, los militares intentaban "mejorar" su imagen bajo el lema: "Mostremos al mundo cómo somos los argentinos", desde el exterior se denunciaba la existencia de campos de concentración, secuestros, torturas y desapariciones. David Viñas y otros argentinos en el exilio conformaron redes de solidaridad que hacía el pueblo argentino. Es en este marco que esta edición de Tiempos Modernos se 
constituyó como una denuncia al régimen y fue leída por sus editores como un esfuerzo de comprensión del fenómeno. No solo se planteaba el desgarro por el exilio, sino que también se intentaba caracterizar la dictadura argentina. Desde la permanencia surgieron otras miradas, se experimentaron algunas tensiones acerca del fenómeno y se puso en cuestión la supuesta inacción de quienes habían permanecido.

Como contrapunto de las reflexiones sobre y desde el exilio, la revista argentina Sitio ${ }^{11}$ publicó un dosier con varios artículos en el que cuestionó la idea de un género identificable como literatura en el exilio, intentando confrontar, en particular, con el número especial de Tiempos Modernos, dirigido por Viñas. Para sus editores, el dosier de Sitio — denominado "Anexo: Del Exilio" — intentó debatir con cierta glorificación exaltada del tema, atravesada por la nostalgia. Se discutía allí con la idea de la existencia de una literatura específica del exilio y se intentaba deconstruir el término en tanto estilo, género y condición.

Varios ejes de discusión estuvieron presentes en los artículos de este número especial de Sitio. En primer lugar, la nota de Jorge Jinkis ${ }^{12}$ apuntó a la necesidad de desarmar un discurso que observaba el país con cierta mirada nostálgica. Jinkis analizó las características de esa construcción sobre el exilio, en el cual aparecía reivindicada y valorada esta condición. Un discurso que, según el autor, se encontraba caracterizado por la nostalgia, la tristeza, la culpa y el desconcierto. Para el escritor, ni el exilio ni la permanencia podían transformarse en valores en sí mismos:

11. La revista Sitio se propuso recuperar el análisis del discurso, la antropología de Lévi-Strauss y el psicoanálisis, así como la importancia de las palabras para enunciar una política literaria.

12. Escritor y psicoanalista nacido en 1943. 
Este artículo está escrito para decir que a todas las estupideces sobre el "ser nacional", desde un lugar inesperado, ha venido a agregarse otra más. Un sujeto sentimentalmente empalagoso, resbaladizo, de afectos chorreantes, levanta un reduccionismo psicológico para elevar como elemento prototípico, como rasgo idiosincrásico de nuestra nacionalidad, la imagen serenísima del dulce de leche. (Jinkis, 1983: 46)

La nota finalizaba polemizando con esta mirada que presentaba a la Argentina como un "tango-canción", y construía así estereotipos de exportación sobre la "identidad nacional". Por su parte, Luis Gusmán ${ }^{13}$ (1983) trazaba una historiografía de la literatura sobre el exilio para intentar leer, desde un punto de vista crítico, un rasgo predominante en ella, consistente en la correspondencia entre las sensaciones del narrador - y su mundo interior - con el mundo político, advirtiendo sobre esta operación de mitologización. En el mismo dosier, Eduardo Grüner ${ }^{14}$ planteaba la idea de "pentimento" — sinónimo de arrepentimiento-, como una pintura que había sido cubierta o transformada, pero que con el paso del tiempo comenzaba a hacer visibles las capas superpuestas de pintura. A partir de esta imagen, intentaba otra vez deconstruir la oposición "afuera"-"adentro": "Suponer la irreductibilidad - o siquiera las relaciones - entre un 'afuera' y un 'adentro' ayuda a dibujar un mito discutible del cualquier tópico (igualmente mítico) del Saber" (Grüner, 1983: 71). Cuestionó entonces la existencia misma de una literatura del exilio, como si fuera posible circunscribirla y distinguir lo interno de lo externo. Para demostrarlo, sostuvo que había mayor relación de "extranjeridad" literaria en Ricardo Piglia y Jorge Asís, siendo que ambos vivían a poca distancia, así como se podía plantear que escritores separados por miles de kilómetros podían tener elementos en común. Grüner recuperó la figura de Ezequiel Martínez Estrada — colaborador en la revista Sur-, quien se situaba "no afuera", sino más allá de la geografía; "no adentro", sino más acá de la historia. Todos los escritos del dosier compartieron la necesidad de un análisis y la deconstrucción de un discurso sobre el exilio que distinguió entre el "afuera" y el "adentro" y los concibió en forma separada y excluyente.

13. Escritor y ensayista nacido en 1944 que formó parte del staff de las revistas Literal, luego Sitio y actualmente, Conjetural, centrada en el psicoanálisis.

14. Escritor, ensayista, sociólogo y docente universitario nacido en 1946. 
Esta tensión, planteada en términos de "divisoria de aguas", también fue percibida y manifestada por los intelectuales del exilio. Al finalizar las diferentes "entradas" propuestas en el dosier especial de Tiempos Modernos, César Fernández Moreno escribía "los que se fueron y los que quedaron":

Los intelectuales argentinos han sido como divididos por una línea esquizofrénica, entre los que se quedaron en la patria y los que se fueron. Conviene decir que unos y otros sufren de un estado de deterioro; es necesario, pues, promover cierta objetividad entre estos argentinos, tanto en los residentes actuales como en los "desinmigrantes". (...) Cuando llegan a su nuevo país, deben preocuparse primero por su alimentación, dicho de otro modo, por su trabajo. Algunos se vuelven, por ejemplo, mozos de café; otros llegan a encontrar una ocupación más cercana a sus costumbres. En los dos casos, se trata de subsistir sin patria. (Fernández Moreno, 1981b: 55)

En todos los casos, se trató de un dilema de difícil resolución: irse o quedarse implicó enfrentar la realidad de la dictadura. Pensar una u otra intervención de forma excluyente exacerbó las tensiones y diferencias entre quienes padecían - afuera y adentro - la censura y persecuciones producto de los mecanismos represivos del régimen argentino. La confrontación se fundó en la necesidad de detenerse en aquellas prácticas que, habiendo tenido lugar en la permanencia aun en condiciones de censura y persecución, hasta el momento no contaban con marcos conceptuales para ser leídas e interpretadas. Aquellas producciones simbólicas gestadas en el "adentro" necesitaban ser enumeradas, nombradas, reconocidas. De esta manera, las polémicas abrieron paso a un momento de creación de condiciones de legibilidad de prácticas de resistencia que, en posdictadura, cobraron nuevos sentidos y dimensiones en su lectura retrospectiva. 


\section{Imagen 2}

Sitio 3. Agosto 1983

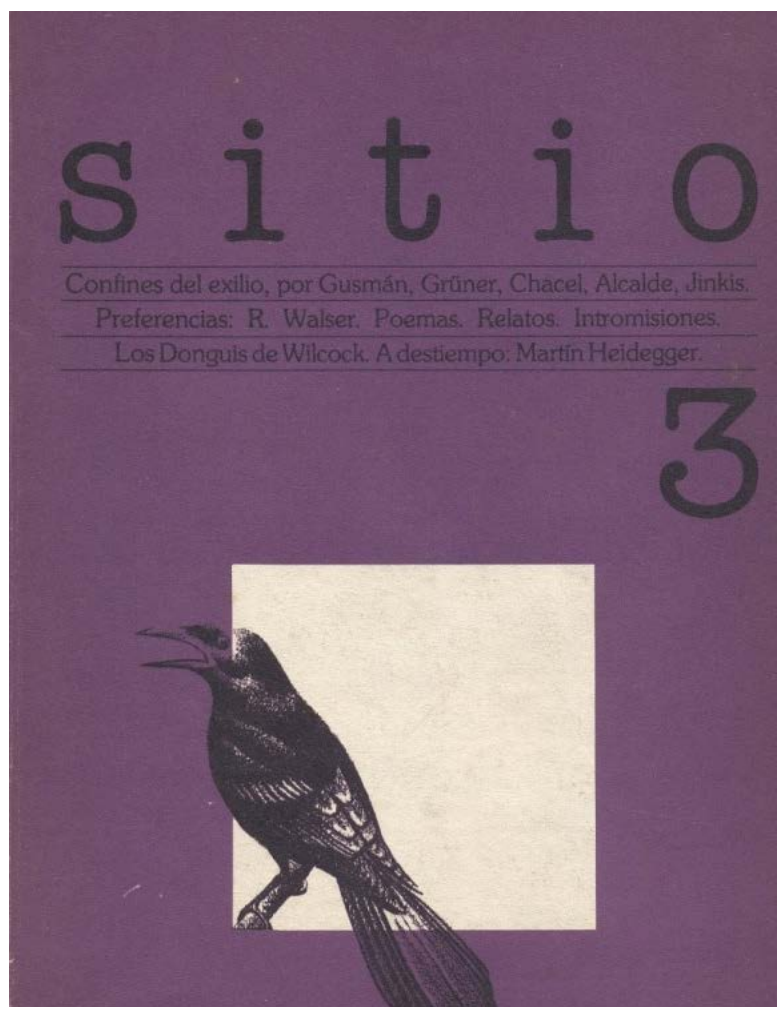

Fuente: Archivo del CeDInCI

\section{2. La idea de "resistencia molecular" en Praxis}

Carlos Brocato (1932-1996) había sido cofundador de la revista La Rosa Blindada en la década de 1960 y contaba con una destacada trayectoria en el campo intelectual. Durante la dictadura y primeros años de la posdictadura argentina, participó como colaborador en los proyectos editoriales de las revistas Nueva Presencia y Praxis. En esta última publicación, editada por primera vez en septiembre de 1983, Brocato debatió con algunos intelectuales en el exilio, identificados por él, en contraposición a aquellos jóvenes que habían permanecido en Argentina. Una generación nueva que, más que centrarse en la crítica "hiperpolitizada" y "castradora" de la tarea cultural, se fue rehaciendo 
lentamente aun en el contexto de la dictadura. Rescataba así a quienes habían permanecido en el país generando iniciativas culturales. Su argumento se centró en la necesidad de nombrar y dar visibilidad a las revistas "subte" y otras prácticas. De esta forma, propuso evitar subestimar los esfuerzos e impulsos de quienes experimentaban ese "otro" exilio desde el sur de Latinoamérica, polemizando con aquellos intelectuales "pequeñoburgueses"15 que no sabían hacer otra cosa que actividades intelectuales, pero que no cesaban de apostrofar contra la eficacia de las mismas. Frente a esta mirada desde el exilio y enfrentándose a ella, se recuperó entonces a esa otra generación más joven y sus producciones culturales - mayoritariamente en formato de revistas-, realizadas en los márgenes y de forma subterránea. Para Brocato, "quedarse" significaba todo lo contrario a la muerte y la inacción. Así lo rescató en ese primer número de Praxis:

\footnotetext{
En medio de una dura represión y censura, a veces vacilando, a veces inclusive a tientas, con la carga sobre sus espaldas de la confusión y la derrota, una dosis de escepticismo que nadie podrá aventarles ya con homilías, hacen revistas (más de cien contabilizaron en la Capital y el Gran Buenos Aires en 1978), arman talleres literarios, se reúnen, a veces los secuestran; cada seis meses regresan a cero, porque la situación económica los diezma. Nadie podrá excusarse si subestima nuevamente este esfuerzo. (Brocato, 1983: 57-58)
}

El análisis funcionó en la revista como un artículo inédito que fue incluido luego en un libro del autor llamado El exilio es el nuestro. En este anticipo del libro en preparación, Brocato otorgó relevancia a las revistas subterráneas, caracterizándolas como un esfuerzo que no había que subestimar o, al menos, del que había que hablar. Su artículo permitió resumir aquellas discusiones que dieron paso a elaborar lecturas, interpretaciones y una terminología muy utilizada en la transición que refirió a la idea de resistencia. Aquella joven intelectualidad significó para Brocato el despliegue de formas de discrepancia y disidencia frente al establishment. La noción de resistencia incluyó diversas prácticas culturales en el contexto de la última dictadura argentina. Sin embargo, Brocato produjo un desvío y una reapropiación de esta idea, al conceptualizarla posteriormente a partir del concepto de resistencia molecular.

15. En su artículo, Brocato confrontaba con Héctor Schmucler, argentino exiliado en México y miembro de la revista Controversia. 
Imagen 3

Praxis 1. Primavera 1983

Fuente: Archivo del CeDInCI

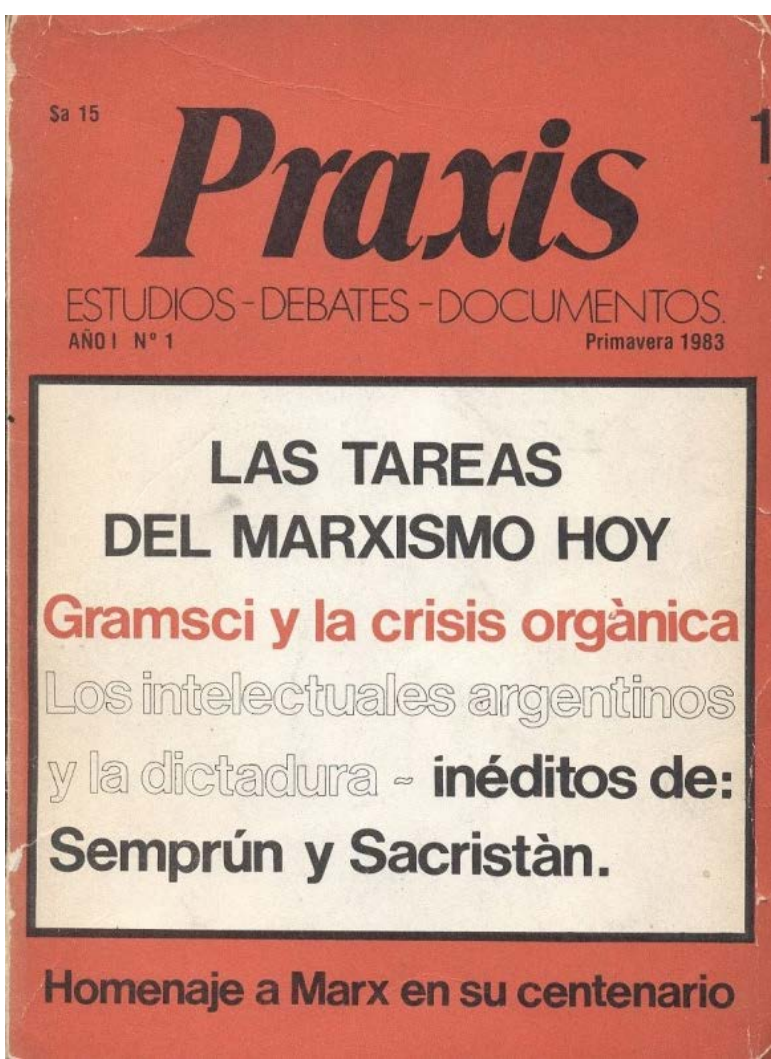

Un tiempo más tarde y ya en posdictadura, al editarse su libro El exilio es el nuestro (1986), este movimiento fue denominado por el autor como "actividad molecular", ubicándolo entre diversos intentos por recomponer el tejido social, establecer vínculos primarios y evitar la dispersión frente a un proceso de fragmentación social. Tales prácticas fueron vistas como la posibilidad de conformar una red de reconocimientos mutuos y generar identidades. La noción de Brocato permitió centrar la mirada en experiencias que desafiaron el poder castrense durante la última dictadura a partir del despliegue de "otras" lógicas vinculadas con la recomposición del entramado social, la generación de conexiones y la articulación de esfuerzos, en contraposición a las estrategias esgrimidas por el poder militar, vinculadas con el despliegue de mecanismos que fomentaron la atomización y la dispersión.

La propuesta de pensar en experiencias que resistieron en algún aspecto los 
mecanismos impuestos por el régimen, surgió también como respuesta a la perspectiva predominante desde el exilio. Brocato se opuso a una mirada -ingenua desde sus términos- que proclamó la autoheroización desde "afuera" y propuso romper con mitos y héroes para reubicar el fenómeno en su complejidad. El artículo, ahora capítulo del libro, señalaba con mayor énfasis el proceso que se había ido gestando: la existencia de un movimiento de resistencia cultural, que había surgido como iniciativa antidictatorial. En su libro cobró forma su idea de resistencia, cuya presencia misma puso en cuestión la mistificación propuesta desde el exilio, que planteaba la inacción en la cultura argentina y, como consecuencia de ello, refería a un "genocidio cultural" ${ }^{16}$ y no solo político:

\begin{abstract}
Adoptaron la imagen, invirtiendo su sentido pero refractándola, que la propia dictadura suministraba. En ese silenciamiento, acallaron toda la cultura de la resistencia con que los que estaban aquí intentaban, bajo la metralleta, preservar los recintos moleculares del pensamiento en libertad. (Brocato, 1986: 151)
\end{abstract}

Esta construcción mitificadora desde el exilio fue producto, para Brocato, de haber tomado las noticias provenientes de agencias internacionales y la prensa masiva comercial. Propuso entonces comprender que los órganos sanos de un cuerpo se podían replegar y "moleculizar". La represión del terrorismo de Estado podía barrer toda actividad cuestionadora, fragmentar el cuerpo social, atomizar las actividades comunitarias y, como consecuencia de este plan salvaje del régimen, ese cuerpo social podía hasta desmembrarse. Sin embargo y en paralelo, cohabitaba una actividad fragmentada y aislada, pero no por ello menos potente y vital:

Porque la resistencia molecular consiste, precisamente, no en intentar recomponer el cuerpo,

16. La idea de "genocidio cultural" había sido gestada desde una publicación desde el exilio (Madrid), titulada Argentina: cómo matar la cultura y en la que colaboraron, entre otros, Julio Cortázar, Miguel Ángel Estrella, Eduardo Galeano, Juan Gelman, Fernando Solanas y Mercedes Sosa. 
pues esto pone al descubierto la actividad y la hace fácilmente vulnerable, sino en reunir los átomos dispersados por el embate represivo y reorganizarlos en torno de pequeños espacios de actividad. De ahí el sentido de "molécula", de actividad "molecular", que explica este viejo dispositivo de los procesos de resistencia. (Brocato, 1986: 152)

Por supuesto que Brocato era consciente de que esos esfuerzos de ninguna manera iban a reconstituir el tejido entero, porque la resistencia cultural, así como la resistencia política habían sido parceladas como consecuencia de los efectos del desmembramiento social y el terrorismo de Estado. Se trató entonces de una resistencia en la derrota y el repliegue. En su argumentación, sostenía que algunos grupos de teatro y las revistas "subte" buscaban una actividad comunitaria que los rescató de la fragmentación y la angustia que impuso la represión, viviendo la experiencia como única forma de afirmación de su ser social. Para el autor, estas iniciativas permitían advertir el desplazamiento hacia estos espacios de una politicidad que, en los espacios tradicionales, se encontraba prohibida:

Del mismo modo en la primera época, la más dura, organizar un asado o un campeonato de truco eran objetivos sindicales preciosos, que empujaban los activistas más conscientes para impedir que el tejido orgánico de la clase obrera se disolviera. Pero, claro, de esto no informaban los diarios ni las agencias internacionales. Los cultores del exilio se olvidaron de todos estos mecanismos universales de la lucha social. No los veían desde Europa y dieron por descontado que no existían. (Brocato, 1986: 154)

Brocato advertía sobre la "miopía" de la intelectualidad en el exilio. Rescataba así 
aquello que hasta el momento no se podía ver o al menos, donde no se había puesto foco: la experiencia de revistas culturales, literarias y underground, fenómeno que, según el autor, irrumpió en 1977 conformando luego la red ARCA junto con otras redes. Las prácticas simbólicas cotidianas eran así analizadas como modos de sociabilidad que permitían recuperar la lucha social y la politicidad que se había perdido. Para el autor, fue posible encontrar allí "militantes de la resistencia". Planteó de este modo, que todo editor responsable, más allá de formar parte de una actividad más espontánea y menos organizada, fue visitado por agentes de servicios que lo interrogaron. Presentó como ejemplos de ello a las revistas subterráneas Cuadernos del Camino (1978-1980), y a Propuesta (1977-1980) ${ }^{17}$, revistas subterráneas surgidas en los primeros años de la dictadura. El análisis de Brocato fue uno de los pocos enfoques que caracterizó y conceptualizó las experiencias de las revistas "subte" contemporáneamente.

Su aporte consistió así en analizar este tipo de publicaciones en el marco de lo que denominó la "resistencia molecular". A lo largo de su recorrido argumentativo, rescató de la mencionada revista contracultural El Ornitorrinco su concepción de que las revistas debían ser comprendidas como un ejercicio de militancia de la literatura. Recuperó además las experiencias de otras revistas subterráneas como Posta (1977-1978) y Nudos (1978-1992) ${ }^{18}$, destacando de ellas la preocupación por registrar expresiones artísticas que no se "sometían". También otorgó valor a la experiencia de la revista Punto de Vista $(1978-2008)^{19}$, de la que reconoció su rigurosidad intelectual y la trayectoria de sus integrantes. Por último, brindó relevancia a otras dos revistas underground - que, surgidas en dictadura, se fusionaron en el último número- como Ulises (1978-1979), a partir de la cual

17. Cuadernos del Camino fue dirigida por Mónica Giustina y posteriormente por Alicia Padura. Propuesta fue dirigida por Silvio Winderbaum y, posteriormente, por Jorge Catania. Aunque el contexto estaba signado por las persecuciones, algunos de sus integrantes se encontraban cercanos al PST (Partido Socialista de los Trabajadores), de orientación trotskista.

18. En 1977, la revista subterránea Posta editó sus tres primeros números en forma bimestral. Luego pasó a llamarse Nudos por razones de registro de propiedad intelectual. Estuvieron dirigidas por Manuel Amigo y Jorge Brega. Algunos de los miembros de la publicación, se encontraban vinculados al maoísmo. Así, la revista se reconoció dentro de una línea vinculada con lo nacional, lo popular y el antiimperialismo.

19. Punto de Vista se propuso un análisis cultural no determinista centrado en el aporte de los Estudios Culturales Ingleses. Sus editores fueron Jorge Sevilla, Beatriz Sarlo y Carlos Altamirano, entre otros. 
un grupo de jóvenes intelectuales había llevado adelante una experiencia de resistencia, y Nova Arte (1978-1980) ${ }^{20}$, cuyos integrantes habían desafiado el miedo desde una escritura crítica y cuestionadora.

Posteriormente en 1993, a propósito de un número especial de la revista Cuadernos Hispanoamericanos, dedicado íntegramente al campo cultural argentino en la última dictadura y los primeros años de la transición, otra vez Brocato retomaba - y complejizaba - la polémica con la idea de genocidio cultural fomentado desde el "mito autoheroizante del exilio", que -como dijimos- identificó la permanencia con cierta inercia. Asimismo, avanzó en la idea de resistencia molecular:

La resistencia de este tipo renuncia tácticamente a reconstruir el cuerpo, porque sabe que es batalla suicida (no proclama, se entiende, la "insurrección" contra la dictadura) y se esfuerza estratégicamente por impedir su atomización. Los propios organismos de derechos humanos se inscriben en este esquema de lucha. (...) ¿En qué foro público, recuperada la democracia, hubo inventario o simple recuerdo de estas actividades y sus protagonistas? (Brocato, 1993: 467-469)

El esfuerzo de Brocato por volver a la memoria ese tipo de experiencias de resistencia significó un ejercicio de visibilización y nominalización. En primer lugar, como dijimos, el trabajo de Brocato se trató de una de las pocas descripciones detalladas de experiencias "subte" y de resistencia, las cuales permanecieron invisibles para gran parte de la intelectualidad. Detenerse en reflexionar sobre ellas les devolvía su protagonismo en la esfera pública. En segundo lugar, demostró su interés por brindar claves de análisis del fenómeno.

En este sentido, se observaba su preocupación por evitar sobredimensionar 20. Ulises tuvo entre sus editores a Horacio Tarcus, Gabriel Rot y Laura Klein (la mayoría con seudónimos por el contexto imperante). Nova Arte fue dirigida por Enrique Záttara. En 1980, ambas revistas se fusionaron en su último número. 
estas prácticas. Para Brocato, ninguna de ellas había proclamado la insurrección contra la dictadura y, sin embargo, habían intentado "juntar células de tejidos". Así comprendió la resistencia: no se podían evadir las leyes del juego —en referencia al terrorismo de Estado- pero se podían articular defensas y ataques para impedir que todo fuera arrasado ${ }^{21}$.

\section{Consideraciones finales: permanencia, exilio y resistencia}

En primer lugar, es importante circunscribir estas discusiones alrededor del exilio como momentos de esfuerzo de inteligibilidad. El exilio significó, en todos los casos, una condición de excepción, una experiencia traumática, un trance doloroso producto de un destierro impuesto. A su vez, la permanencia implicó padecer persecuciones, generar condiciones de resguardo y protección, experimentar formas de decir, hurgar en el límite entre lo permitido y lo prohibido y conformar redes de solidaridad para enfrentar la lógica de dispersión desplegada por el poder militar.

Como analizamos en el trabajo, en el momento de la transición se multiplicaron algunas polémicas y tensiones entre exilio y permanencia que generaron como consecuencia una línea divisoria entre el afuera y el adentro. No obstante, desde el exterior se generaron redes de solidaridad con el pueblo argentino, denunciando las aberraciones cometidas por el régimen. Exilio y permanencia fueron consecuencia de los mecanismos de control, censura y persecución desplegados por el terrorismo de Estado. En particular, desde la permanencia, se generaron una serie de intervenciones tendientes a dar voz - y condiciones de legibilidada prácticas invisibles hasta ese momento.

Una serie de confrontaciones alrededor del exilio, como las descritas a lo largo

21. El pensamiento de Deleuze y Guattari (1977) tiñó también, al menos en algunos aspectos, la reflexión de Carlos Brocato (1986) al plantear la idea de "molecularidad", la que daba cuenta de un "tejido social" que se encontraba dañado en sus células. Esta idea de resistencia "molecular" presente en el pensamiento de Brocato fue el punto de partida para esbozar ciertas metáforas que intentaron identificar las múltiples formas posibles que se entretejieron para recomponer ese tejido y superar la atomización y fragmentación social. 
del trabajo, constituyeron modos de intervención que permitieron recuperar el valor de experiencias que, aunque gestadas en lo micro, incidieron en el tejido social. A pesar de que no conformaron un ejercicio de insurrección, implicaron un desafío, un esfuerzo de socialización y a su vez, un intento de ser nombradas y visibilizadas. La "resistencia molecular" significó entonces quebrar la dispersión y crear un campo común de inquietudes.

Estas claves de lectura permitieron pensar en experiencias diversas y múltiples que conformaron iniciativas que, desde la micropolítica, construyeron conexiones, tramas y relaciones, desafiando en algún aspecto la tendencia a la atomización y la segmentación social.

La transición implicó volver a mirar estas prácticas, renombrarlas, ubicarlas en una nueva dimensión: no se trató de prácticas contrahegemónicas y sin embargo, se propusieron recomponer en algún sentido el tejido dañado. Junto a otras, permiten constatar la existencia de una "otra cultura" u otras prácticas, situadas en el borde, en los márgenes, desafiantes y resistentes.

Las discusiones de quienes se habían quedado en Argentina se propusieron romper con una mirada que identificó la permanencia con la inacción o el aquietamiento. Muchos de quienes permanecieron, lo hicieron participando en proyectos culturales que dinamizaron el campo cultural. A la vez, es innegable que tanto quienes se quedaron como quienes se vieron obligados a optar por el exilio experimentaron "desgarros" y "dolores" que fueron producto de los dispositivos de control y persecución del régimen militar.

Una mirada retrospectiva nos permite plantear que aquel dilema, fue complejizado 
por nuevas miradas que intentaron comprender el exilio y la permanencia, ambos como producto de la desarticulación y fragmentación social que había instaurado el terrorismo de Estado. Sin embargo, las polémicas permitieron nombrar y describir ciertas prácticas ubicadas "en los márgenes".

De esta forma, las confrontaciones analizadas permitieron tensionar el espacio público tanto "adentro" como "afuera". Hacer públicas las diferencias, narrar los desgarros tanto desde la condición exiliar como desde la permanencia, fueron acciones que implicaron desafiar y alterar la lógica hegemónica del poder militar argentino, tendiente a sofocar cualquier tipo de expresión crítica. 


\section{Bibliografía}

- BROCATO, C. (1983). La intelectualidad y la crítica del balazo. Praxis, (1), 5758.

- BROCATO, C. (1986). El exilio es el nuestro. Los mitos y los héroes argentinos. ¿Una sociedad que no se sincera? Buenos Aires: Sudamericana Planeta.

- BROCATO, C. (1993). Cultura y mitos argentinos. Cuadernos Hispanoamericanos, (517-519), 465-469.

- CAlveiro, P. (1998). Poder y desaparición. Buenos Aires: Colihue.

- CANELO, P. (2008). El proceso en su laberinto. La interna militar de Videla a Bignone. Buenos Aires: Prometeo.

- CANElo, P. (2016). La política secreta de la última dictadura. Buenos Aires: Edhasa.

- CORTÁZAR, J. (1978). América Latina: exilio y literatura. Eco, (205), 59-66.

- CORTÁzAR, J., \& HEKER, L. (1981). Exilio y Literatura (II) Polémica. El Ornitorrinco, (10), 3-7.

- CRISTIÁ, M. (2017). Imaginación y resistencia antidictatorial en los años ochenta. La acción por América Latina de la Asociación Internacional de Defensa de Artistas Víctimas de la Represión en el Mundo (AIDA). Revista Izquierdas, (36), 156-180. Recuperado de http://www.izquierdas.cl/images/pdf/2017/ n36/art7.pdf

- DE DIEGO, J. L. (2007). ¿Quién de nosotros escribirá el Facundo? Intelectuales y escritores en Argentina (1970-1986). La Plata: Ediciones Al Margen.

- DELEUZE, G., \& GUATTARI, F. (1977). Rizoma (Introducción). Valencia: PreTextos. 
- FERNÁNDEZ MORENO, C. (1981a). Las ilusiones del enamorado. Les Temps Modernes, (420-21), 29-30.

- FERNÁNDEZ MORENO, C. (1981b). Los que se fueron, los que quedaron. Les Temps Modernes, (420-21), 55-56.

- FRANCO, M. (2008). El exilio. Argentinos en Francia durante la dictadura. Buenos Aires: Siglo XXI.

- FRANCO, M. (2018). El final del silencio. Dictadura, sociedad y derechos humanos en la transición (Argentina, 1979-1983). Buenos Aires: Fondo de Cultura Económica.

- GRAZIANO, M. (1980). Para una definición alternativa de la comunicación. Revista ININCO, (1), 71-74.

- GRÜNER, E. (1983). La Argentina como pentimento. Sitio, (3), 71-83.

- GUSMÁN, L. (1983). Del destierro al exilio: versiones e inversiones. Sitio, (3),61-70.

- HEKER, L. (1980). Exilio y literatura: Polémica con Cortázar. El Ornitorrinco,(7), 3-5.

- JINKIS, J. (1983). La Argentina, tango-canción. Para desmontar un discurso. Sitio, (3), 39-48.

- LESGART, C. (2002). Ciencia política y producción de la idea de transición a la democracia. La reorganización de un campo del conocimiento. En A. FERNÁNDEZ (Comp.). La ciencia política en la Argentina. Dos siglos de historia. Buenos Aires: Biebel.

- MARCUS, C. (2002). Las revistas culturales subterráneas en la dictadura. Ponencia llevada a cabo en las II Jornadas de Historia de las Izquierdas. CeDInCI, Buenos Aires.

- PATIÑO, R. (2006). Revistas literarias y culturales argentinas de los 80. Usinas para pensar una época. Ínsula, Revista de letras y ciencias humanas, (715-716), $2-5$. 
- RISLER, J. (2019). La Acción Psicológica. Dictadura, inteligencia y gobierno de las emociones. Buenos Aires: Tinta Limón.

- RIVERA, J. (1995). El periodismo cultural. Buenos Aires: Paidós.

- SIMPSON GRINBERG, M. (1986). Comunicación alternativa: tendencias de la investigación en América Latina. En M. SIMPSON GRINBERG (Comp.), Comunicación alternativa y cambio social (pp. 23-55). México: Premia editora.

- VIÑAS, D. (1981). Los militares argentinos de 1930 a 1980. Les Temps Modernes, (420-21), 44-45.

- VIÑAS, D. \& FERNÁNDEZ MORENO, C. (2011). Revista Tiempos Modernos. Argentina: entre populismo y militarismo. Buenos Aires: Biblioteca Nacional.

- WILLIAMS, R. (1988). Marxismo y Literatura. Barcelona: Península 


\section{Biografía}

\section{Evangelina Margiolakis}

Universidad de Buenos Aires, Argentina

emargiolakis@gmail.com

Doctora en Ciencias Sociales de la Universidad de Buenos Aires. Licenciada en Ciencias de la Comunicación Social de la misma universidad. Su tesis doctoral se encuentra en prensa y se titula: "La conformación de una trama de revistas culturales subterráneas en dictadura y sus transformaciones en postdictadura". Directora del Proyecto UBACYT: "Políticas comunicacionales, modos de intervención cultural y campo intelectual argentino en dictadura y postdictadura. Entre lo hegemónico y lo contracultural", con sede en el Instituto de Investigaciones Gino Germani (UBA). Forma parte del Grupo de Estudio sobre Arte, Cultura y Política en la Argentina Reciente, dirigido por Ana Longoni en el Instituto Gino Germani (UBA). Jefa de Trabajos Prácticos en Didáctica de la Comunicación en la Facultad de Ciencias Sociales (UBA). Adjunta a Cargo en Teoría de los Medios y la Cultura en la Facultad de Filosofía y Letras (UBA). 